\title{
Filstotorias
}

(PPGHIS/UnB) No. 33, Brasília, Ago - Dez 2018 ISSN 2316-1191

DOI: 10.26512/emtempos.v1i33.23683

Recebido: 07/10/2018

Aprovado: 01/12/2018

\section{Samuel Wainer: entre Diretrizes e Ultima Hora}

Thiago Fidelis ${ }^{1}$

Resumo: O presente artigo tem como objetivo discutir uma parte da trajetória de Samuel Wainer, jornalista que entrevistou em 1949 Getúlio Vargas, em sua propriedade no interior do Rio Grande do Sul. Dentre os vários assuntos discutidos, o então senador e ex-presidente teria declarado que seria novamente candidato ao posto máximo do Executivo na eleição do ano seguinte. A partir daí Wainer, que durante o governo de Vargas teve sua revista, Diretrizes, fechada por conta da ação da censura e exilou-se para fugir da repressão do Estado Novo, acabou se aproximando do político gaúcho e foi um dos repórteres que acompanhou toda a candidatura vitoriosa de Getúlio. Pouco tempo depois da posse, em 1951, o jornalista fundou o jornal Ultima Hora, publicação que disputaria espaço no campo jornalístico para, ao contrário dos outros diários, defender o governo e o legado de Vargas, buscando direcionar as ações do mandatário de maneira positiva. Assim, foi discutido o caminho de Wainer entre Diretrizes e Ultima Hora, indicando como o então perseguido político passou a

\footnotetext{
${ }^{1}$ Doutor em Ciências Sociais pela Unesp. Trabalho vinculado à tese de doutorado, financiado pela CAPES. E-mail: fidelisrp@gmail.com
} 
ser uma das figuras mais próximas de Vargas durante seu último governo (19511954).

Palavras-chaves: Samuel Wainer; Diretrizes; Ultima Hora.

Abstract: The main purpose of this paper is to discuss Samuel Wainer's trajectory as the journalist who interviewed Getúlio Vargas, in 1949, in the Rio Grande do Sul (Brazil) countryside ex-president's property. Among all the issues addressed, the Senator (at that moment) Vargas suggested he would be a candidate for the maximum public position in Brazilian Executive System during the elections of the following year. From this moment on, Wainer, who, in Vargas's first government, was forbidden to publish the magazine Diretrizes because of the censorship; and who exiled himself to escape the repression of the New State, just approached the politician and became one of the most important journalists who followed Getúlio's victorious campaign. After the Presidential inauguration (1951), the journalist created the paper Ultima hora, a publication that would fight for space in the journalistic field, because, unlike other newspapers, it defended government and Vargas's legacy, seeking to direct the actions of the representative in a positive way. Thus, the objective of our research was to discuss Wainer's "evolution" from Diretrizes to Última hora, indicating how the victim of political persecution converted himself in one of the characters who were closer to Vargas in his last government (1951-1954).

Keywords: Samuel Wainer; Diretrizes; Ultima Hora.

Na campanha eleitoral de 1950, a figura de Getúlio Vargas foi extremamente combatida pelos jornais de maior tiragem no país, desejosos de aniquilar a movimentação eleitoral do ex-presidente. Sua candidatura ganhou proporções nacionais a partir de uma reportagem feita por Samuel Wainer, repórter dos Diários Associados (DA), que funcionou como uma espécie de estopim para a mobilização do então senador rumo à presidência.

O jornalista viajou até ao Rio Grande do Sul para fazer uma reportagem sobre as plantações de trigo da região e, após sobrevoar propriedades do então senador em São Borja, decidiu tentar conversar com o proprietário, já que ele era cotado como um possível nome para a eleição presidencial em 1950. A entrevista foi concedida e a candidatura confirmada (WAINER, 1988, p. 26-29), após questionamentos em relação à política nacional. Nas próprias palavras do jornalista:

- $\quad$ E se o senhor viesse a ser candidato? - perguntei.

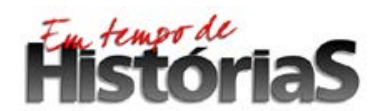

(PPGHIS/UnB) No. 33, Brasília, Ago - Dez 2018 ISSN 2316-1191 
- $\quad$ Eu não sei... - começou Vargas. - Mas pode dizer uma coisa: eu voltarei (...) Tremi. Ele pronunciara duas palavras mágicas. Desde que Getúlio deixara o poder, pichações em muros de centenas de cidades do país repetiam uma frase: "Ele voltará". Agora a frase era formulada na primeira pessoa. Em seguida, repetiu as palavras mágicas e acrescentou uma ressalva que cairia como uma bomba sobre o mundo políticobrasileiro:

- Eu voltarei. Mas não como líder de partidos, e sim como líder de massas (...) Fui para o aeroporto e voei para São Paulo. Na segunda-feira passei pela sede dos Diários Associados, na rua 7 de abril, e deixei uma cópia da reportagem na mesa de Assis Chateaubriand, acompanhada de várias fotos. Segui para o Rio de Janeiro. Como não se imprimiam jornais durante o carnaval, tampouco na Quarta-Feira de Cinzas, eu teria de esperar pela quintafeira para ver impresso o resultado da minha entrevista com Getúlio. Valeu a pena esperar: como previa Pasqualini, foi uma bomba que, detonada na fronteira gaúcha, espalharia estilhaços por todo o país (WAINER, 1988, p. 22-23).

Na reportagem publicada no dia 03 de março, com grande destaque em O Jornal, a fala de Vargas não apontava para uma volta imediata (como colocada no livro de memórias do jornalista), sendo que ele se declarava um líder de massas e que agiria como tal (O Jornal, “O DEBATE DA SUCESSÃO PRESIDENCIAL NÃO PODERÁ SER MAIS CONTIDO”, 03/03/1949). Ainda assim, o efeito da publicação da entrevista foi bastante importante, uma vez que, embora muito se especulasse sobre a postura do expresidente e suas possíveis movimentações em relação à candidatura, não havia nada ainda documentado sobre o assunto.

Mesmo sem ser anunciada oficialmente, a candidatura de Vargas começou a ganhar apoio e, consequentemente, o ataque de vários órgãos da imprensa foi acentuado, sendo que publicações como O Estado de S. Paulo (OESP) e O Globo foram umas dessas principais vozes de oposição. Enquanto isso, Wainer passou a acompanhar o político gaúcho como enviado especial dos DA e tornou-se um dos principais divulgadores de sua campanha, gerando uma situação bastante peculiar, já que o dono dos DA, Assis Chateaubriand (mais conhecido como Chatô) defendia a candidatura de Canrobert Pereira (e, depois que essa não foi estruturada, passou a apoiar o candidato do governo Dutra, Cristiano Machado) e fazia ataques diretos ao ex-presidente em seus editoriais, com um ritmo bastante frequente.

Assim, nas edições de sua empresa, era possível ler reportagens dando detalhes da campanha do ex-presidente com uma perspectiva bastante positiva de seus possíveis

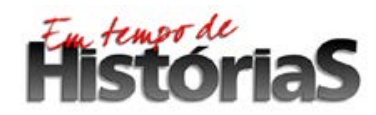


resultados e, ao mesmo tempo, ler um editorial extremamente crítico em relação a Vargas ou à sua movimentação política. Por exemplo, em um dos vários textos publicados e assinado por Wainer, Getúlio teria atestado para outros jornalistas que tudo o que o funcionário dos DA escrevia era balizado por ele próprio:

O Sr. Getúlio Vargas recebeu a imprensa (...) palestrando durante 45 minutos com os jornalistas e respondendo às suas perguntas. Sobre a sua impressão da excursão que vem realizando ao norte do país, Getúlio, sorrindo, perguntou aos interpelantes: "Vocês não lêm as crônicas de Samuel Wainer? Pois eu subscrevo tudo o que ele escreve” (...) (O Jornal, Subscrevo todas as crônicas escritas por Samuel Wainer, 02/09/1950).

No dia seguinte, em seu texto no editorial, a publicação carioca minimizou a viagem feita por Vargas aos estados do Norte e Nordeste brasileiro, além de chamar a atenção para o fato do "fracasso" de sua chegada ao aeroporto no Rio de Janeiro após tal movimentação:

O sr. Getulio Vargas regressou ontem de sua excursão de quatorze dias pelo norte e nordeste do país. Veio naturalmente cansado, não só da viagem longa como do sacrifício a que foi submetido, obrigado a falar em todos os comícios (...) Mas ao aqui chegar, supunha, talvez que seria recompensado com uma recepção grandiosa, com uma multidão incontavel a se espraiar pelas redondezas do aeroporto e a gritar o seu nome. O que ocorreu, entretanto, foi coisa muito diferente. Não correspondeu presentes á intensa propaganda que desde pela manhã se fazia em todos os bairros da cidade (...) Mais decepcionante ainda, foi o seguinte: depois do desembarque e de receber abraços e vivas dos correlegionários, dentro da estação, o sr. Getúlio Vargas entrou num automóvel fechado e partiu em disparada rumo a sua residência, deixando os que se deram ao incômodo de ir presenciá-lo de perto a ver navios (...) (O Jornal, NÃO CORRESPONDEU À ESPECTATIVA, 03/09/1950).

Ainda na mesma edição, foi publicado um texto (sem assinatura) intitulado CONTRA O POVO, no qual fazia acusações a Vargas de que ele não recebia e nem se importava com a população em geral, utilizando-a apenas para sua ascensão política (O Jornal, CONTRA O POVO, 03/09/1950). Assis Chateaubriand apoiou, em seus textos,

\section{Filistororias}


Cristiano Machado; no entanto, mesmo com críticas contundentes a Vargas e aos outros concorrentes, não fechou o espaço de sua cadeia a nenhum deles, permitindo colunas ou reportagens favoráveis a qualquer um dos outros nomes (MORAIS, 1994, p. 494). Além disso, continuou investindo em Samuel Wainer e seu acompanhamento da campanha de Vargas, até o final da movimentação.

Em outubro de 1950, o então senador venceu a eleição, derrotando novamente o candidato da UDN, Eduardo Gomes. Como era esperado, a imprensa voltou-se inteiramente contra tal ponto, buscando explicações para o que parecia inexplicável. Em seu editorial, por exemplo, OESP não perdoou o eleitorado, os partidos políticos e o próprio Vargas pelo seu resultado vitorioso:

O candidato democratico, por excelencia, foi vencido pelo candidato antidemocratico, também por excelencia. Ao paladino da justiça e da lei preferiu o eleitorado o paladino do totalitarismo e da violencia. (...) Que é que resta aos democraticos fazerem diante da vontade do eleitorado assim manifestada nas urnas? (...) Em 1945, deposto o ditador, coube aos democratas a tarefa de restaurar o regime da lei, elaborando uma constituição que o consagrasse integralmente. Bem ou mal, essa tarefa foi cumprida. Agora, com a vitoria do ex-ditador nas urnas, compete-lhes o trabalho de amparar as instituições que estabeleceram. Esse trabalho não o levarão a termo se, seduzidos pelos cantos de sereia do ex-ditador a seus companheiros, perderem o ardor combativo e derem por consolidado definitivamente $\mathrm{o}$ regime que a Constituição de 1946 consagrou (...) O que se pede, em suma, aos democratas genuinos é que saibam conservar-se á distancia razoavel do governo e que não se lancem, precipitadamente, ao primeiro aceno amistoso, nos braços do homem que rasgou duas constituições e suprimiu, durante anos, todas as liberdades que o povo estava habituado a desfrutar (...) O que se espera, em suma, dos democratas verdadeiros é que tenham um pouco de juizo e, principalmente, que tenham um pouco de vergonha (OESP, A posição dos partidos, 17/10/1950).

As primeiras ações de Vargas como presidente foram cobertas com um viés bastante negativo pelos principais veículos de comunicação do país, que acompanhavam suas movimentações a distância e criticavam, praticamente, todas as suas ações. Samuel Wainer era um dos poucos repórteres que acompanhavam a movimentação presidencial, mantendo a lógica incutida por Assis Chateaubriand, que ainda utilizava um de seus grandes desafetos políticos como um dos principais chamativos de seus jornais.

A partir desses aspectos, Vargas teria proposto ao Profeta (apelido dado ao jornalista pelo presidente) a criação de um jornal que procurasse acompanhar melhor o

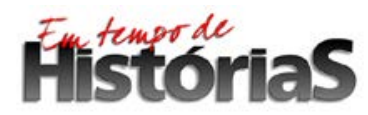


governo e cobrir de maneira positiva suas causas (defendendo seus pontos de vista). Segundo relato do próprio Wainer:

- $\quad$ Por que tu não fazes um jornal?

Respondi que aquele era um sonho de um repórter com o meu passado. Ponderei que não seria difícil articular a montagem de uma publicação que defendesse o pensamento do presidente que, como era o seu caso, tinha o perfil de um autêntico líder popular.

- $\quad$ Então, faça - determinou Getúlio. Perguntei-lhe se queria saber como faria.

- $\quad$ Não - cortou. Troque idéias com a Alzira e faça rápido reagi com o entusiasmo de sempre:

- $\quad$ Em 45 dias dou um jornal ao senhor.

- $\quad$ Então, boa noite, Profeta - encerrou Getúlio.

- $\quad$ Boa noite, presidente.

A Ultima Hora começava a nascer e eu a encontrar a minha razão de viver (WAINER, 1988, p. 127).

Em 12 de junho de 1951, nasceu o periódico Ultima Hora (UH), com o intuito de defender os posicionamentos do governo Vargas, mas também de aproximar-se mais da população com menor renda da cidade (já que ler jornal ainda era um hábito caro e pouco comum). Para isso, a estratégia utilizada pela equipe editorial do jornal foi de não falar somente de política em suas páginas, mas também de abordar outros temas mais “próximos” à população como questões do cotidiano, cultura e esporte, entre outros. Diferentemente de boa parte dos jornais da época, em suas primeiras edições a UH costumava não separar os temas por páginas ou cadernos. Desse modo, em uma mesma página era possível encontrar comentários políticos, uma notícia sobre um assassinato no centro do Rio de Janeiro e uma nota sobre uma peça que seria encenada no Teatro Municipal, por exemplo.

Além disso, o jornalista Edmar Morel (um dos primeiros contribuidores da UH) publicou em seu livro de memórias que o periódico seria o primeiro a utilizar outdoors, anúncios no rádio, outros periódicos e também propaganda na TV para divulgar seu lançamento, evidenciando a intensa busca da publicação em se estabelecer já como uma grande marca no meio dos outros impressos (MOREL, 1999, p. 187).

Na coluna à esquerda da capa da primeira edição, há uma carta de felicitação mandada por Vargas para o jornal, na qual o presidente reconheceu a importância da publicação para a democracia do país, indicando a necessidade de um novo canal popular de comunicação. Ao mesmo tempo, como manchete principal a publicação trazia uma

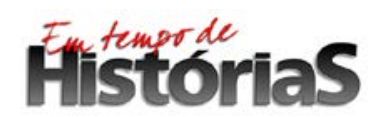


denúncia às péssimas condições da Central do Brasil, principal estação de trem do Rio de Janeiro, indicando que a UH estava ao lado do presidente, mas, ao mesmo tempo, atenderia as demandas da população, buscando denunciar as más condições das estruturas públicas da capital e de todo o país.

Nessa primeira edição foi inaugurada também a coluna $O$ Dia do Presidente, que trazia o cotidiano do mandatário brasileiro tanto em ações políticas quanto em aspectos comuns, utilizando uma tática bastante interessante de procurar aproximar o leitor da figura humana de Getúlio, e não apenas de seu já conhecido lado político ou institucional. Partindo dessa perspectiva, o jornal passou a ter um número expressivo de tiragens e grande sucesso, conseguindo concorrer diretamente com os principais diários do Rio de Janeiro e de São Paulo (BARROS apud CAMPOS, 1993, p. 63-71).

O diário carioca também é apontado como um celeiro de nomes de destaque da imprensa brasileira no período, abrindo espaço para profissionais que se tornariam referências jornalísticas no cenário nacional ${ }^{2}$. Além desse ponto, a publicação também inovou em relação à estrutura gráfica, trazendo a capa e alguns pontos dentro de sua publicação em cores (em especial o logo, um azul que se tornaria sua marca registrada), além de quebrar um protocolo muito comum entre os diários em geral no

\footnotetext{
${ }^{2}$ No início da publicação, o jornal contou com profissionais como o jornalista Luís Fernando Bocayuva Cunha (sua assinatura no jornal era como L. F. Bocayuva Cunha), que exercia também o cargo de diretor superintendente da publicação; o colunista Manuel Bernardes Muller (que assinava no jornal como M. Bernardes M.), costumeiramente apontado como o criador da coluna social na imprensa brasileira e que também utilizava (em várias outras publicações nas quais ele também trabalhava) o codinome Jacinto Thormes; Medeiros de Lima, um dos principais colunistas políticos do período; o jornalista português radicado no Brasil Tomás Ribeiro Colaço (que escrevia sobre Portugal e outros países europeus); o escritor e notório representante do PCB na redação, Octávio Malta (que já trabalhara com Wainer em outro empreendimento, a revista Diretrizes); o experiente fotojornalista Daniel Caetano; o poeta, cantor e diplomata Vinícius de Moraes (que escrevia sobre cinema no jornal); o escritor Marques Rebelo (que discutia teatro em sua coluna); o artista plástico Augusto Rodrigues; o jornalista esportivo Álvaro Paes Leme; o famoso caricaturista argentino Lorenzo Molas (criador dos principais mascotes dos clubes cariocas e da Argentina); o jornalista esportivo Caio de Nassau; o escritor e dramaturgo Nelson Rodrigues, que desenvolveria a famosa coluna A Vida Como Ela É; o já famoso jornalista Edmar Morel; o escritor Francisco de Assis Barbosa; o caricaturista e pintor argentino André Guevara (que criou todos os logotipos e design gráfico do jornal, considerado extremamente inovador para a época); o famoso

jornalista esportivo Albert Laurence; a dramaturga Olga Obry, além do quadrinista estadunidense Monte Hale, entre outros nomes, que passaram pelos mais de 20 anos de existência do jornal.
}

\section{Filistororias}


Brasil, que ostentavam seu nome no clichê principal da capa. No caso da UH, o logo sempre esteve presente, mas não, necessariamente, em posição centralizada, deslocandose conforme as manchetes e as imagens estruturadas.

Mas, afinal, quem era Samuel Wainer? Levando em conta a trajetória dos grandes grupos de mídia impressa até então existentes no Brasil, seus donos geralmente eram famílias ligadas ao poder ou a grandes conglomerados financeiros (BAHIA, 1990, p. 227). No entanto, Wainer não pertencia a nenhum desses grupos. Nasceu em 1910 e era filho de imigrantes que vieram da distante Bessarábia, região do Leste Europeu (atualmente fragmentada em vários outros países, como a Moldávia e Ucrânia), sendo que seu local de nascimento foi objeto de muita polêmica ao longo de toda sua vida, sempre permeada por incertezas se ele nascera ainda na região de origem de seus progenitores ou se viera ao mundo em território brasileiro (ROUCHOU, 2004, p. 153158).

Passou a infância em São Paulo e, devido às poucas condições financeiras da família, mudou-se para o Rio de Janeiro para morar com familiares, exercendo desde adolescente a função de jornalista e passando pelos principais diários do Rio de Janeiro. Em 1938, foi convidado pelo famoso jornalista Antônio José de Azevedo Amaral para auxiliá-lo em uma nova publicação, a revista Diretrizes. Tal empreendimento, com frequência mensal, surgiu com a proposta de ser um semanário que trataria de várias temáticas (seu subtítulo era Política, Economia, Cultura), embora com a perspectiva política sempre destacada.

O fundador da revista era médico, com inúmeros trabalhos já no jornalismo e com várias obras relacionadas à política, defendendo os regimes de exceção e justificando a intervenção do Estado na sociedade e limitações à liberdade de expressão (fato esse bastante curioso). No mesmo ano do início da circulação da revista, o autor publicou a obra O Estado Autoritário e a Realidade Nacional, no qual fez uma defesa contundente dos regimes autoritários e justificou o novo regime de Vargas, indicando sua necessidade e possíveis benefícios para a população, que deveria, em contraponto, seguir alguns aspectos (AMARAL, 1981, p. 1996)

Já bastante debilitado fisicamente (viria a falecer quatro anos depois do lançamento da revista) e praticamente sem visão, Azevedo Amaral contratou Wainer para assessorá-lo na revista (tinham trabalhado juntos no Almanaque Israelita (AI), um dos primeiros trabalhos do jovem bessarabiano). O autor possuía intensa participação em 
sociedades cariocas israelitas, que promoviam jornais, revistas próprias e participavam de publicações cariocas (seja com publicidade ou artigos próprios) para difundir princípios ou ideias ligadas ao judaísmo.

Foi nesse contexto que ambos se conheceram. Embora a data não seja precisa (as únicas referências ao assunto são as memórias do próprio Wainer), o futuro dono da UH começou escrevendo para um jornal da Associação dos Estudantes Israelitas, depois migrando para o DN, no qual ficou encarregado de escrever uma coluna para a divulgação da cultura israelita e aspectos da colônia judaica no Rio de Janeiro. Antes de chegar à parceria com Azevedo, Wainer passou por vários outros empreendimentos, como a escrita de textos no próprio AI; posteriormente, na Revista Brasileira (RB), também traduzindo para essa publicação artigos da revista Francesa Le Mois; fundou, com apoio financeiro e intelectual de Caio Prado Júnior (com quem trabalhara na RB), a Revista Contemporânea (RC) que durou menos de um ano; e, por fim, passou a trabalhar para seu antigo companheiro de AI, em 1937, transcrevendo seus textos, distribuindo-os para os vários periódicos com os quais o tradicional jornalista brasileiro contribuía (DUQUE FILHO, 2007, p. 54-57).

Próximo de várias figuras da empresa canadense de eletricidade Light and Power, Amaral conseguiu financiamento para o lançamento de Diretrizes em 1938, cuja tessitura era ligada aos acontecimentos da política nesse contexto. Embora o médico e jornalista fosse o diretor e criador da revista, cujo primeiro número saiu em abril, a revista foi orientada, de fato, por Wainer, até por conta da limitação física de Amaral. Mesmo sendo secretário particular do já consagrado escritor brasileiro, suas ideias não eram próximas, principalmente em relação à política, uma vez que o fundador da UH colocava-se como um pensador de esquerda, mas não comunista (WAINER, 1988, p. 47-48), orientação bastante distinta de seu chefe.

Seis meses depois, Amaral abandonou a revista pela incompatibilidade de ideias entre a equipe formada e as suas. Praticamente todos os nomes da publicação possuíam textos e laços com grupos de esquerda e com o Partido Comunista do Brasil (PCB), com uma visão bastante crítica ao Estado Novo, sendo incompatível com a perspectiva do fundador da publicação. A partir da edição de novembro, Wainer teria o total controle de Diretrizes, que contava com nomes como o jornalista e poeta Alvaro Moreyra, o jornalista Carlos Lacerda, o militar e historiador Nelson Werneck Sodré, o escritor

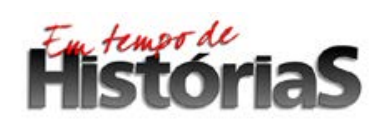


Graciliano Ramos, o delegado e escritor Rubem Braga, entre outros (FERRARI, 2012, p. 138).

O antigo diretor da revista fundou uma nova publicação, intitulada Nova Diretrizes (ND), levando o financiamento da Light para esse empreendimento e fazendo com que Wainer passasse a buscar patrocínio de outros grupos, recebendo inclusive apoio financeiro da propaganda do governo, mesmo com textos muitas vezes críticos a algumas posturas do líder político nacional (FERRARI, 2012, 138-139).

As revistas não chegaram a rivalizar diretamente (até porque se distanciaram cada vez mais em relação às suas linhas editoriais) e seguiram caminhos opostos: com maior liberdade dentro da redação, Amaral passou a orientar praticamente a ND inteira para apoio incondicional a Vargas e às políticas cada vez mais autoritárias, valorizando os discursos já conhecidos em suas obras nas páginas de sua revista. A publicação durou apenas até sua morte, não prosseguindo após o desaparecimento de seu principal mentor.

Em compensação, a perspectiva de Diretrizes era cada vez mais eclética e voltada aos valores democráticos e de contestação ao autoritarismo e ao fascismo, em um período em que o Departamento de Imprensa e Propaganda (DIP) estruturava seu amplo controle sobre a produção cultural do país (CAPELATO, 2009, p. 81-82). A revista reunia um número ainda maior de nomes identificados com a esquerda e com aspectos democráticos, embora também mantivesse nomes mais conservadores e até de apoiadores do regime. Entre os novos colaboradores após sua "nova fase”, pode-se destacar as presenças de Moacyr Werneck de Castro, Astrogildo Pereira, Joel Silveira (que se tornou secretário de redação), Osório Borga, Marques Rebelo, Genolino Amado, Adalgiza Nery (esposa de Lourival Fontes) e os jovens escritores Jorge Amado e Rachel de Queiróz, entre outros (DUQUE FILHO, 2007, p. 82-83).

Por conta desse perfil, a publicação era visada em praticamente todos os meses e passou a ser consultada antes de sua publicação. Em linhas gerais, Diretrizes passou a se aproximar cada vez mais dos ideais democráticos, tendo como base o modelo estadunidense (não à toa, grande parte da publicidade vinha de empresas desse país) e também com vários textos próximos à linha defendida pelo PCB que, embora na ilegalidade, tinha ainda várias atividades, tendo como prática comum a presença de seus representantes nos meios de comunicação (FERRARI, 2012, p. 140-141).

Mesmo com o cerco do governo e com os escassos anúncios (a eclosão da guerra em 1939 tornou a situação econômica bastante grave e complexa), a revista seguiu 
mensalmente até 1941, quando passava por grave situação financeira. Após buscar recursos com vários de seus contatos para manter sua publicação, Wainer conseguiu uma grande quantia de Maurício Goulart, ex-aliado de Vargas (colaborara com a Revolução de 1930) e agora opositor ao regime (FERRARI, 2012, p. 142-143).

A partir desse contexto, a revista passou a ser semanal e agregou ainda mais jovens nomes da intelectualidade nacional, tais como Gilberto Freyre, Artur Ramos, Cassiano Ricardo, Sérgio Millet, Manuel Bandeira e José Lins do Rego (FERRARI, 2012, p. 144) e, por conta disso, passou a ter cada vez mais problemas com o DIP, principalmente pela presença de Goulart na redação (já que ele tinha sido preso por envolvimento com a Aliança Nacional Libertadora, em 1935), sendo que vários textos relacionados a acontecimentos recentes do país eram constantemente censurados pelo órgão estatal.

Após inúmeros cortes, em 1944 o fornecimento de papel para a impressão foi suspenso em definitivo e, por conta disso, a revista deixou de circular. A “gota d’água”, segundo Wainer, teria sido a publicação do texto Vinte e dois dias que abalaram o Brasil, no qual comemorava os 20 anos do movimento tenentista liderado por Miguel Costa, Isidoro Dias Lopes e Juarez Távora. Embora a reportagem não fizesse nenhum ataque ao governo diretamente, exaltava o clima de liberdade e busca pela consolidação de ideias democráticas e de um país com maior abertura política ${ }^{3}$.

A partir da suspensão da revista e pelos inúmeros questionamentos feitos em audiência com membros do governo e do DIP (como tentativa de reverter a situação, embora sem sucesso), Wainer acabou exilado e passou pelo Chile, Estados Unidos (onde ficou boa parte do tempo) e México (FERRARI, 2012, p. 146-150). O fechamento da revista, embora de certa forma sempre visto como uma possibilidade pelos seus membros, não deixou de causar grande impacto, principalmente para seu organizador:

\footnotetext{
${ }^{3}$ Algumas obras da bibliografia costumam indicar um outro motivo para o fim da circulação de Diretrizes, que teria sido uma entrevista concedida por Lindolfo Collor, ex-ministro do Trabalho de Vargas, a Francisco de Assis Barbosa em 02/07/1942, indicando que, após o fim da Segunda Guerra Mundial e o possível triunfo dos Aliados, a democracia deveria voltar a triunfar no país. Por essa entrevista, Collor foi preso e, mesmo liberto, acabou morrendo poucos meses depois (BRUINELLI, 2013). Também há uma outra versão, ainda mais disseminada, de que o fim de Diretrizes teria sido causado por uma outra entrevista, concedida por Monteiro Lobato a Joel Silveira, publicada no dia 06/09/1943, cuja chamada de reportagem fora uma frase do famoso escritor, indicando que "UM GOVERNO DEVE SAIR DO POVO COMO A FUMAÇA DE UMA FOGUEIRA”. Nessa reportagem, Lobato fez vários elogios a temáticas como a democracia e à organização social na URSS, entre outros. No entanto, Diretrizes fechou apenas no ano seguinte à tal publicação (SILVEIRA, 2001, p. 82-83).
}

\section{Hilistorias}


Entre abril de 1938 e julho de 1944, Diretrizes sustentou contra o DIP uma luta sem tréguas, apoiada pelo entusiasmo ideológico e pela capacidade intelectual de cada um de seus oponentes. Essas virtudes compunham seu capital. Em 1944, a revista estava profissionalizada, mas devia sua sobrevivência à visão romântica que tínhamos do jornalismo. Faltavam anunciantes, faltava capital, a venda em bancas não bastava para assegurar salários justos para os homens que faziam a revista e a dívida com a gráfica aumentava. Ainda assim, prosseguíamos. Também o eterno combate de gato e rato travado com o DIP começava a nos cansar (...) No primeiro semestre de 1944, contudo, a luta contra toda espécie de adversidade se mostrava demasiado exaustiva. Hoje tenho consciência de que, nessa época, comecei a provocar o fechamento de Diretrizes, pautando ou fazendo pessoalmente reportagens sobre temas considerados tabus (WAINER, 1988, p. 66$67)$.

Pouco mais de um ano após o exílio, voltou ao Brasil e retomou a publicação de Diretrizes, mas dessa vez com o formato de jornal (embora em suas páginas ainda estivesse grafado o termo “revista semanal”). No entanto, a aventura (como ele próprio relata) duraria pouco tempo, uma vez que percebera (de maneira tardia, como também relembrou em suas memórias) que manter uma publicação diária demandava um trabalho muito maior do que ele imaginara com suas edições semanais, além de que havia também um custo mais elevado do que o esperado. Assim, já em 1945 acabou vendendo o periódico para o ex-interventor paulista João Alberto e rumou para a Europa, tornandose correspondente internacional do próprio periódico (WAINER, 1988, p. 83-85) até 1947.

Durante seu período de exílio, trabalhou como correspondente do Globo, escrevendo inúmeras reportagens para o jornal de Roberto Marinho. Dentre as várias reportagens de destaque, foi publicada sua cobertura sobre assuntos relacionados à Segunda Guerra Mundial e, em especial, uma reportagem que, segundo o próprio Wainer, teria sido encomendada pelo dono do jornal, sobre a filha de Luís Carlos Prestes, Anita Leocádia (WAINER, 1988, p. 81). Após encontrá-la no México junto de familiares, o jornalista fez uma longa reportagem com várias fotos (inclusive pequenos textos e desenhos enviados pelo líder político do PCB à filha) e seu texto ganhou destaque na capa da edição do dia 16/03/1945, com o título A MENINA BRASILEIRA QUE AINDA NÃO CONHECE O BRASIL. Em suas memórias, Samuel indicou que, ao voltar ao Brasil em 1945, foi levado ao presídio no qual o dirigente comunista estava preso para

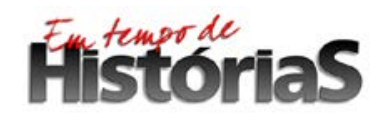


falar sobre sua filha, mas acabou sendo repreendido por ter exposto a garota, dessa forma, na reportagem (WAINER, 1988, p. 83-84).

Quando voltou a exercer a função de correspondente após a venda de Diretrizes, teve como grande destaque a cobertura do julgamento de inúmeros oficiais nazistas em Nuremberg, na Alemanha. Único jornalista brasileiro que acompanhou in loco os acontecimentos, o próprio Wainer descreveu em suas memórias como conseguiu estar lá, uma vez que as credenciais foram disputadas por jornalistas do mundo todo (WAINER, 1988, p. 85). Segundo seus próprios apontamentos, ele estava em Paris na época em que foi informado que aconteceria tal julgamento e não queria perder a oportunidade de presenciar um momento considerado histórico. Além disso, é necessário também levar em conta sua origem judaica que, embora nunca muito problematizada pelo autor, foi sempre um aspecto bastante presente em sua trajetória e sua porta de entrada no jornalismo (ROUCHOU, 2004, p. 133-134).

Wainer também soube que o embaixador estadunidense em Paris no momento era Jefferson Caffery, que tinha sido até 1944 embaixador no Brasil e com quem o jornalista travara certa proximidade. A partir disso, não hesitou em procurar o diplomata uma vez que, das 450 credenciais para jornalistas disponíveis, 300 eram para os profissionais estadunidenses e as outras 150 estavam sendo disputadas por europeus e soviéticos (principalmente por representantes de países envolvidos diretamente nos conflitos) e, após conseguir uma audiência, procurou convencê-lo da importância de se ter um jornalista brasileiro na cobertura, já que o Brasil também participara do conflito (WAINER, 1988, p. 86).

Após conseguir as credenciais, viajou de Paris a Nuremberg e ficou cerca de 120 dias acompanhando todo o processo (o julgamento durou dez meses), intercalando as estadias na Alemanha com viagens por várias partes da Europa, sempre em busca de reportagens no campo político e aproveitando as facilidades que seus contatos permitiam para obter furos de reportagem como o julgamento de Vichy em Paris, dos franceses que colaboraram com os nazistas na ocupação durante os acontecimentos do início dos anos 1940 (WAINER, 1988, p. 94).

Além dessa cobertura, escreveu uma série de reportagens sobre os displaced people, grupo de descendentes de alemães ou estrangeiros que, por problemas de documentação ou por restrições diplomáticas (muitos deixaram seus países durante a Segunda Guerra e foram defender a Alemanha no conflito), não estavam regularizados 
no país, mas também não podiam deixá-lo (WAINER, 1988, p. 97-98). Essa série de entrevistas teria causado grande impacto ao jornalista, uma vez que ele teria pensado até em escrever uma peça baseada nos relatos (ROUCHOU, 2004, p. 95-98), pois a situação desses apátridas era, de certa forma, a sua condição: no Brasil, era o judeu que buscava seu espaço entre seus habitantes; na Europa, era o brasileiro que também buscava firmarse entre outros povos. Sempre era o diferente, o outsider, o apátrida. Tal condição, de certa forma, acompanhá-lo-ia em sua trajetória jornalística, principalmente após fundar a $\mathrm{UH}$.

Após retornar ao Brasil, em 1947, Wainer deixou Diretrizes por perceber que o diário havia tomado um rumo bastante distinto de seu período, indicando um tom mais sensacionalista e com um enfoque mais “popularesco" (WAINER, 1988, p. 84-85), sendo que o jornal parou de circular em 1948. Logo que se desligou de seu antigo periódico, foi contratado por Assis Chateaubriand e passou a trabalhar como repórter em O Jornal, um dos inúmeros periódicos da imensa cadeia do empresário paraibano. Viajando pelo Brasil (e também algumas vezes para fora dele, a fim de cobrir eventos como o da criação do Estado de Israel, em 1948), o jornalista trabalhou com inúmeras matérias que versavam sobre os mais variados assuntos, indicando uma versatilidade que agradava bastante ao dono do periódico no qual trabalhava.

Dentro dessa perspectiva, a viagem aos campos de trigo no Rio Grande do Sul em 1949 tinha como objetivo buscar uma questão para se chegar à outra. Segundo o próprio Wainer, a ideia de Chatô era desencorajar seus leitores de que o Brasil deveria ser autossuficiente na produção de trigo para não perder mercado com os argentinos (já que esses eram os maiores fornecedores do país), sendo que as reportagens deveriam corroborar esse princípio para manter a dependência brasileira a grupos internacionais que controlavam esse mercado (WAINER, 1988, p. 113-114). Contrariado, o jornalista começou a fazer um levantamento minucioso dos produtores e da produção na região, percebendo que o Brasil tinha capacidade para produzir mais trigo do que a demanda nacional e que suas conclusões iriam contra os princípios do dono do jornal (se fizesse a reportagem com o teor que achava correto, provavelmente pagaria por isso com seu próprio emprego).

No entanto, em uma das viagens à região próxima de Porto Alegre, em conversas informais com alguns acompanhantes e com o piloto (Nelson da Gama e Souza, exmembro da Força Expedicionária Brasileira), descobriu que Vargas estava recebendo

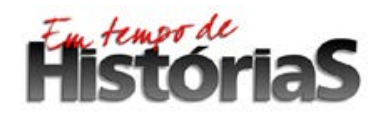


algumas pessoas, esporadicamente, na sua instância Itu, em São Borja. O repórter decidiu realizar a viagem e, embora com recomendações dos acompanhantes de que não seria recebido pelo ex- presidente e então senador, decidiu arriscar:

Estávamos nas imediações de Bagé, e perguntei ao piloto quanto tempo levaríamos para chegar a São Borja. Duas horas, calculou Nelson. Eram duas da tarde. Então, murmurei, chegaremos às quatro. $O$ piloto pareceu espantar- se.

- O Senhor pretende ir lá? - quis saber. Confirmei.

- Não faça isso, porque ele não recebe - disse Nelson (...)

- Nelson, o avião é meu e nós vamos para lá - disse. Se ele me receber, farei uma bela reportagem. Caso contrário, farei uma reportagem dizendo que ele não recebe ninguém (WAINER, 1988, p. 20).

Rumaram à estância de Vargas e, de maneira bastante simpática, o proprietário recebeu Wainer e começou, não necessariamente, a responder perguntas, mas sim a expor sua opinião sobre a política do período e sobre a eleição que se aproximava. Após refletir sobre várias possíveis candidaturas, acabou indicando a própria (embora sempre de maneira indireta, nunca enfática), incitando Wainer a divulgá-la ${ }^{4}$.

\footnotetext{
${ }^{4}$ Há outras versões para o acontecimento. No início dos anos 1950 (já após a criação da UH), Assis Chateaubriand defendeu a ideia, no texto "Uma história mal contada", publicado na revista $O$ Cruzeiro, de que a entrevista já era premeditada e que não fora divulgada na época para não causar grande alarde, uma vez que já havia grande movimentação para a "volta" de Vargas ao cenário nacional, sendo que Wainer teria sido o repórter escolhido. Tal versão foi confirmada por alguns nomes que trabalhavam no DA da época, como Carlos Castelo Branco e Austregésilo de Athayde (MORAIS, 1994, p. 495). Poucos anos após o lançamento da biografia de Wainer, o assessor de imprensa de Getúlio Vargas durante seu último governo, Rivadavia de Souza, lançou um livro para fazer contraponto a várias afirmações do dono da UH, taxando-as de mentirosas. Entre elas, o jornalista afirmou que quem lançou a candidatura de Vargas, na verdade, foi a seção paulista do PTB, fator que teria causado a ira do senador gaúcho (SOUZA, 1989, p. 28-29), sendo que a reportagem de Wainer teria sido mais uma, entre tantas outras, sobre a possível entrada de Getúlio na disputa. Recentemente, o jornalista Lira Neto publicou uma trilogia sobre a biografia do político gaúcho e, na última edição (que comporta o período de 1945 a 1954), sustentou uma outra versão, indicando que, ao analisar as correspondências entre o político gaúcho e sua filha Alzira, notou que havia um acordo entre membros da UDN e do PSD para que um repórter do DA fosse até o sul arrancar uma declaração positiva do senador em relação à figura de Eduardo Gomes, candidato derrotado em 1945 e que seria lançado novamente pelos udenistas. Ainda dentro dessa visão, Wainer não teria sido o repórter escolhido para promover tal ação, mas sua entrevista acabou servindo a esses propósitos (LIRA NETO, 2014, p. 158-175), já que nessa conversa o político gaúcho tecera elogios ao Brigadeiro. No entanto, independente das motivações, a repercussão da reportagem foi enorme no país todo, por vários motivos.
} 
A partir daí a discussão sobre candidatura de Vargas ganhou musculatura (FERREIRA, 2011, p. 60-63) e teve início uma fase importante na vida do jornalista, pois toda essa movimentação daria origem à UH. Naturalmente, a publicação entrou em rota de colisão com outras publicações e nomes da imprensa, como as acusações de financiamento de maneira ilícita (por ter recebido verbas do governo) e de que Wainer não podia ser dono de jornal por ser estrangeiro ${ }^{5}$, o que causou grandes problemas para a publicação, que se manteve fiel à defesa dos grupos ligados ao legado varguista até suas últimas páginas, mesmo no período ditatorial pós 1964 (LAURENZA, 1998, p.122-125).

Em linhas gerais, é possível identificar que Wainer entrara, definitivamente, no mundo dos proprietários de jornais a partir desse novo empreendimento, com forte apoio governamental e com muitas das idealizações e novidades já apresentadas em Diretrizes e atualizadas pela sua vasta experiência como repórter. Assim, o jornal tinha início sobre o capital cultural de seu criador e de sua equipe (boa parte já havia trabalhado junta na década de 1930 e 1940), com um forte apoio político (o que implicava, também, em um grande capital econômico).

A própria origem dessa nova publicação evidenciava uma disputa política que refletia diretamente no campo da imprensa, sendo que a cultura política trabalhista, representada por Vargas e pelo PTB, buscava um espaço maior nesse segmento, já que todo o restante dos periódicos (com pontuais exceções) fazia intensa oposição ao político gaúcho, tendo destaque as maiores publicações do país: GLOBO, OESP e Jornal do Brasil (JB).

Entre a imprensa com maior número de tiragem, nesse contexto, UH ganhava cada vez mais força e passava, aos poucos, a se consolidar entre os jornais de maior alcance na capital brasileira e em todo o país (LAURENZA, 1998, p. 52). E justificando a sua criação, trabalhava como um contraponto bastante enfático em relação às publicações em sua maioria na época, sendo que desde seus primeiros dias o periódico fez defesa pontual do governo. O fundador do jornal mantinha, na primeira página da publicação, um espaço diário intitulado Coluna de Ultima Hora, na qual escrevia (embora

\footnotetext{
${ }^{5}$ A Constituição brasileira autorizava que os meios de imprensa fossem controlados apenas por pessoas nascidas no país; embora toda sua família viesse da Bessarábia, o dono do jornal argumentou que nascera no Brasil, fato esse que nunca foi comprovado; em seu livro de memórias, que foi publicado após sua morte, Wainer assumiu que, de fato, não tinha nascido em território brasileiro, embora chegara aqui ainda com cerca de 2 anos de idade (ROUCHOU, 2004, p. 157).
}

\section{Fillstortorias}


intercalasse, muitas vezes, com outros jornalistas) sobre várias temáticas de cunho social e, principalmente, de bases políticas. No dia 07/07/1951, por exemplo, estruturou um texto que demonstrava bem a posição do jornal frente a insinuações de alguns deputados da oposição de que Vargas arquitetava um plano contra a democracia:

O discurso de ontem do sr. Getulio Vargas constituiu nova reafirmação de sua disposição de manter-se como principal sentinela do sistema democratico do país. A cordialidade e o respeito com que o atual Chefe de Governo se dirigiu ao Congresso, representaram o mais cabal desmentido aos tendenciosos rumores, espalhados antecipadamente por alguns circulos udenistas, sobre pretensos ataques ao Poder Legislativo que aquele discurso conteria (...) Devese ainda notar que ao contrario do sucedido no governo anterior, que gozou de uma paz parlamentar unica, o atual governo tem contra si uma oposição extremamente combativa, vigilante e ardorosa. Esse fato amplia ainda mais a importancia das referencias feitas pelo sr. Getulio Vargas aos senadores e deputados em cujas mãos depositou a chave da recuperação financeira do país (...) (UH, Coluna de Ultima Hora Samuel WAINER, 07/07/1951).

Com essa perspectiva, o jornal procurou consolidar-se como o principal representante, na imprensa, do governo Vargas e de suas demandas, estruturando sua própria cultura política em convergência com os pressupostos do governo. Ao mesmo tempo em que a publicação desenvolvia métodos próprios em prol de sua identidade, criava ambiente para a divulgação e disseminação das demandas defendidas pelo Executivo federal, que não encontrava espaço entre os periódicos de grande circulação (CARVALHO, 2012, p. 32).

De modo geral, a UH apresentou, em suas páginas, perspectivas bastante distintas das apresentadas pela imprensa em geral. Os principais aspectos da cultura política do jornal foram estruturados com base no capital de seu fundador e, de certa forma, da equipe formada desde o grupo de Diretrizes, com uma pauta defendendo interesses nacionalistas, buscando o desenvolvimento do capitalismo pela intervenção do Estado, dando maior importância aos interesses nacionais perante os estrangeiros (embora não negasse a participação desses investimentos no país).

Não era contra o capital privado, mas defendia seu uso perante regulamentação do Estado. Além disso, também voltava sua atenção para as demandas dos trabalhadores, procurando abrir espaço para os interesses e a situação do chamado cidadão comum, aquele que não estava envolvido nem no domínio dos meios de produção nem 
diretamente com as instituições políticas, tirando seu sustento da venda de sua força de trabalho.

A defesa dos pressupostos do governo Vargas seria uma espécie de convergência, já que boa parte do habitus do presidente era defendido pela UH. O jornal surgiu, então, como um elemento de disputa dentro do campo, buscando um espaço pelo viés da imprensa que, na leitura do político gaúcho e de seus assessores próximos, não existia ou era extremamente diminuto. O próprio surgimento desse periódico foi estruturado como uma ação efetiva política, procurando espaço no campo político para o estabelecimento do sistema republicano.

Nesse caso, a disputa seria em torno da legitimação de um novo governo, que trazia elementos condenados pelos principais veículos de imprensa no período. Em uma das primeiras edições, em editorial, a UH comentou as críticas que vinha recebendo por ser um pretenso jornal oficioso, procurando especificar que tinha sua própria identidade, não estando apenas a reboque de Vargas:

\begin{abstract}
No entanto, nem todos souberam compreender o pronunciamento do sr. Getulio Vargas. A carta do Presidente deu margem a que fossem tecidas sórdidas explorações, a nosso respeito, por jornais tendenciosos, que passaram a apontar-nos como "órgão oficioso do governo" (...) Não. Não somos um orgão oficioso do governo. Somos um jornal livre e independente. E podemos afirmá-lo, á luz do sol, sem temer a invectiva dos nossos adversarios. Muitos jornais, que se intitulam oposicionistas, atacando o governo com mão de gato, mas recebendo por detrás da cortina gordas propinas, subvenções e estipendios duvidosos, talvez não possam, como nós, proclamar essa liberdade e essa independencia (...) Ao sr. Getulio Vargas, não é segredo para ninguém, prendem-nos laços de grande afetividade pessoal. Mas a amizade do Presidente, que só nos pode honrar, não significará, de forma alguma, obstaculo para que saiamos da rota que nos traçamos, desde o primeiro numero de ULTIMA HORA: o nosso jornal será, antes de mais nada, um jornal do povo para o governo, e nunca um jornal do governo para o povo. O futuro confirmará o que o presente já pronuncia (UH, Coluna de Ultima Hora Samuel WAINER, 29/06/1951).
\end{abstract}

Por fim, é importante salientar que a publicação, ao se colocar como defensora de valores que eram caros ao governo Vargas (e não defensor do político em si), buscava independência de ação, mas sem negar sua perspectiva política. Assim, com um misto do jornalismo combativo, politicamente, do século XIX, com uma visão mais empresarial e estratégica do século XX, Wainer buscou a fórmula para manter a UH como um dos principais jornais do país (GOLDSTEIN, 1993), com grande circulação até o ano

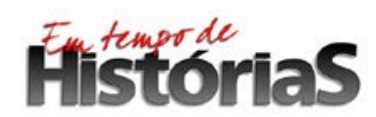

(PPGHIS/UnB) No. 33, Brasília, Ago - Dez 2018 ISSN 2316-1191 
de 1964, criando surcursais em cinco estados (São Paulo, Minas Gerais, Rio Grande do Sul, Paraná e Pernambuco), além da nova capital, Brasília. Entre a militância política e a sobrevivência econômica, o jornalista acabou criando um dos principais canais de fomentação e divulgação da cultura política trabalhista no Brasil, cujo principal símbolo era o de Getúlio Vargas.

\section{Referências bibliográficas}

AMARAL, Azevedo. $O$ Estado autoritário e a realidade nacional. Brasília: Editora Universidade de Brasília, 1981.

BAHIA, Juarez. Jornal, história e técnica. História da imprensa brasileira. 4 ed. São Paulo: Editora Ática, 1990.

BARROS, Theodoro de. Imprensa era dominada por um grupo familiar até 1950. In: CAMPOS, Anderson (org.). Nos tempos de Wainer: a Última Hora de Samuel. Rio de Janeiro: ABI-Copim, 1993.

BRUINELLI, Tiago O. LINDOLFO COLLOR: múltiplas narrativas. Dissertação (mestrado) - Universidade do Vale do Rio dos Sinos, Programa de Pós-Graduação em História, São Leopoldo, RS, 2013.

CAPELATO, Maria H. R. Multidões em cena: propaganda política no varguismo e no peronismo. 2 ed. São Paulo: Editora Unesp, 2009.

CARVALHO, Aloysio C. O caso Última Hora e o cerco da imprensa ao Governo Vargas. Niterói: Editora Nitpress, Ediotra da UFF, 2012.

DUQUE FILHO, Álvaro X. Política internacional na revista Diretrizes (1938-1942). Assis, 2007. Dissertação de Mestrado - Faculdade de Ciências e Letras de Assis - Universidade Estadual Paulista.

FERRARI, Danilo W. A atuação de Joel Silveira na imprensa carioca (1937-1944). São Paulo: Cultura Acadêmica, 2012.

FERREIRA, Jorge. João Goulart: uma biografia. $3^{\circ}$ ed. Rio de Janeiro: Civilizaçao Brasileira, 2011.

GOLDSTEIN, Gisele. Do Jornalismo Político à Indústria Cultural. São Paulo: Summus, 1987 (Novas buscas em comunicação; v. 19).

Jornal O Estado de S. Paulo. Edições de 1950.

Jornal O Jornal. Edições de 1949 a 1950.

Jornal Ultima Hora. Edições de 1951.

LAURENZA, Ana M. de A. Lacerda x Wainer - $O$ corvo $e$ o bessarabiano. $2^{\circ}$ ed. São Paulo: SENAC, 1998.

LIRA NETO, José. Getúlio: da volta pela consagração popular ao suicídio (1945-1954). São Paulo: Companhia das Letras, 2014.

MORAIS, Fernando. Chatô: o rei do Brasil. São Paulo: Companhia das Letras, 1994.

MOREL, Edmar. Histórias de um repórter. Rio de Janeiro: Record, 1999.

ROUCHOU, Joelle. Samuel: duas vozes de Wainer. Rio de Janeiro: UniverCidade Editora, 2004.

\section{Filistororias}


SILVEIRA, Joel. Memórias de alegria. Rio de Janeiro: Mauad, 2001.

SOUZA, Rivadavia de. Botando os pingos nos is: as inverdades nas memórias de Samuel Wainer. Rio de Janeiro: Record, 1989.

WAINER, Samuel. Minha razão de viver: memórias de um repórter. Rio de Janeiro: Record, 1988. 